\title{
Reseña de Sentencias del Tribunal Constitucional sobre la Administración Local y Autonómica que aparecen publicadas en el B.O.E. durante el primer trimestre de 1993
}

\author{
Francisco Javier Fernández González \\ Seminario de Derecho Administrativo \\ Universidad de Oviedo
}

\begin{abstract}
Sumario: I. FUENTES: A) Decretos-Leyes. B) Legislación básica. C) Leyes de Presupuestos. II. ORGANIZACIÓN ADMINISTRATIVA. III. HACIENDAS LOCALES. IV. EMPLEO PÚBLICO. V. CARGOS PÚBLICOS. VI. RÉGIMEN ELECTORAL. VII. ACTOS ADMINISTRATIVOS. EJECUTIVIDAD. VIII. POLICÍA: A) Policías Locales. B) Agentes Rurales. IX. DERECHO PUBLICO DE LA ECONOMIA: A) Entidades de crédito y Cajas de Ahorro. B) Transportes terrestres.
\end{abstract}

\section{FUENTES}

\section{A) Decretos-Leyes}

1. Recurso de inconstitucionalidad 706/1986, interpuesto por el Gobierno Vasco contra los arts. 1, 2, 4, 5 y Disposición transitoria primera del Real Decreto Ley 1/1986, de 14 de marzo, de medidas urgentes administrativas, financieras, fiscales y laborales, por supuesta transgresión del art. 86.1 de la CE. El Decreto Ley si bien no puede alterar el régimen constitucional de las Comunidades Autónomas, sin embargo, puede regular materias en las que una Comunidad Autónoma tenga competencias, pero en las que incida una competencia legislativa del Estado. El Decreto Ley puede, asimismo, establecer disposiciones legislativas que contengan bases o normas básicas.

«Se plantea en el presente recurso de inconstitucionalidad si los artículos recurridos del Decreto Ley van más allá de las limitaciones constitucionalmente impuestas al contenido de este tipo de normas, que establece el art. 86.1 CE, a "alterar el régimen de las Comunidades Autónomas", y la inadecuación del Decreto Ley para fijar las bases normativas previstas en el art. 149.1.18.CE. 
En relación con la primera objeción, ha de tenerse en cuenta que el art. 86.1 CE utiliza un término "régimen de las Comunidades Autónomas" más extenso y comprensivo que el mero de "Estatuto de Autonomía", por lo que dicha expresión ha de ser interpretada, como ha dicho la STC 29/1986, "en el sentido de que el Decreto Ley no puede afectar al régimen constitucional de las Comunidades Autónomas, incluida la posición institucional que les otorga la Constitución". De ese "régimen constitucional" forman parte los Estatutos, que no pueden ser alterados por un Decreto Ley, pero también se incluyen otras leyes estatales atributivas de competencias, que forman parte del bloque de la constitucionalidad, así como las leyes atributivas de competencias del art. 150.1 CE, las Leyes de armonización del art. 150.3, y las Leyes Orgánicas a que se refiere el art. 150.2 CE. Por tanto, el Decreto Ley no puede regular objetos propios de aquellas leyes que, conforme al art. 28.1 LOTC, hayan sido aprobadas, dentro del marco constitucional, para delimitar las competencias del Estado y de las diferentes Comunidades Autónomas o para regular o armonizar el ejercicio de las competencias de éstas.

Más allá de ese "régimen constitucional" en el campo normativo de los Decretos Leyes se corresponde con la competencia legislativa del Estado, no existe obstáculo constitucional alguno para que el Decreto Ley, en el ámbito de la competencia legislativa que corresponde al Estado, pueda regular materias en las que una Comunidad Autónoma tenga competencias, pero en las que incida una competencia legislativa del Estado, siempre que esa regulación no tenga como fin atribuir competencias o delimitar positivamente la esfera de competencias de las Comunidades Autónomas.

Ciertamente, el ejercicio de las competencias de un ente puede afectar en alguna medida a las del otro. Pero cuando la Constitución veda al Decreto Ley "afectar" al régimen de las Comunidades Autónomas, se refiere a una delimitación directa y positiva de las competencias mediante tal instrumento normativo, y no a cualquier regulación que indirectamente "incida" en las competencias autonómicas. De otro modo, se vaciarían prácticamente de contenido los ámbitos de regulación sobre los que el Decreto Ley puede proyectarse, puesto que es muy difícil encontrar un objeto normativo en el que no incida de uno u otro modo alguna competencia autonómica.

En el presente caso, los preceptos impugnados, que regulan materias del procedimiento administrativo, no afectan ni delimitan la esfera de competencias propias de la Comunidad Autónoma, por lo que no infringen el límite establecido en el art. 86.1 CE» (vid. f. j. 2. ${ }^{\circ}$ ). 
JURISPRUDENCIA

«Según la Comunidad Autónoma recurrente, los preceptos impugnados serían contrarios al art. 149.1.18 CE, porque el Decreto Ley no es un instrumento adecuado para establecer bases o normas básicas, que deben aprobarse por una Ley votada en Cortes.

Resulta necesaria una precisión previa. La Constitución, en su art. 149.1.18, emplea diversas técnicas de distribución competencial, y de reserva de competencias al Estado. El precepto reserva al Estado las "bases del régimen jurídico de las Administraciones Públicas y del régimen estatutario de sus funcionarios". Pero no emplea el mismo criterio (distinción entre bases y desarrollo) al reservar in toto al Estado la competencia sobre "procedimiento administrativo común". Es ésta, pues, una competencia exclusiva del Estado, y no reducida al establecimiento de bases o normas básicas...

Las normas impugnadas suponen una importante innovación en nuestro ordenamiento jurídico, puesto que, conforme a los arts. 94 y 95 de la Ley de Procedimiento de 1958, siempre que no se previera un régimen especial, el silencio era negativo y producía la denegación presunta de la petición una vez denunciada la mora y transcurrido el plazo de 3 meses sin notificarse la resolución. En cambio, conforme al art. 1 del Decreto Ley objeto del presente recurso y en la materia allí descrita, la regla general es el silencio administrativo positivo, salvo en las materias expresamente previstas en el anexo. Esta innovación, con distintos matices y supuestos, ha sido en la actualidad adoptada con carácter general por la Ley 30/1992... en sus arts. 42 y 43.

Tal técnica se integra en el procedimiento administrativo encaminado a la producción de actos, en lo que aquí atañe, al modo de una autorización concedida por la Administración. Que este extremo del procedimiento administrativo debe resultar "común" en todo el Estado, en el sentido querido por el art. 149.1.18 de la Constitución, se justifica en la necesidad de que esa garantía mínima que redunda en beneficio de los administrados juegue por igual para todos los españoles que dirigen sus peticiones para la instalación de empresas a la Administración.

A la misma conclusión habría de llegarse también si se considerasen como bases o normas básicas los preceptos impugnados. Es cierto que la jurisprudencia constitucional ha insistido en la preferencia de la norma legislativa sobre la norma reglamentaria para el establecimiento de bases y normas básicas, pero esa jurisprudencia trata de acentuar la reserva de Ley y reducir la intervención del Reglamento en la materia, sin haberse planteado la problemática específica del 
Decreto Ley. Por ello, la referencia que esa jurisprudencia hace a la Ley votada en Cortes en oposición al Reglamento, no puede ser entendida como una exclusión del Decreto Ley para establecer una legislación de carácter básico. A efectos de la legislación básica sólo juega el límite específico del art. 86.1 CE ("régimen de las Comunidades Autónomas"), siendo posible que el Decreto Ley, siempre que se cumplan los demás requisitos constitucionales exigibles, establezca "disposiciones legislativas" que contengan bases o normas básicas también a los efectos del art. 149.1.18 CE.

Por consiguiente, los preceptos impugnados no vulneran el art. 149.1.18 CE""(vid. f. j. 3..$^{\circ}$.

«No existe motivo alguno para considerar que el Decreto Ley sea inconstitucional desde la óptica de la inexistencia de las razones de urgencia y necesidad que constituyen su presupuesto habilitante, puesto que el Gobierno actuó dentro del margen de apreciación política de las situaciones de urgencia que, de acuerdo con la Constitución le habilita para dictar Decretos Leyes, y según las facultades que a este órgano constitucional le incumben para la gobernación del país, en general, y para dirigir la actividad económica en particular, todo ello de acuerdo con los arts. 86.1 y 97 de la Constitución» (vid. f. j. 6).

Fallo: Desestimar el presente recurso de inconstitucionalidad.

(Sentencia n. ${ }^{\circ}$ 23/1993, de 21 de enero. BOE 24-2-1993. M. RodríguezPiñero y Bravo-Ferrer).

\section{B) Legislación básica}

1. El Consejo Ejecutivo de la Generalidad de Cataluña y el Gobierno Vasco promueven los conflictos de competencia 591/1986, 604/1986, $1137 / 1987$ y 1325/1987, relacionados todos ellos con la materia de Mutualidades de Previsión Social no integradas en la Seguridad Social y frente a las siguientes disposiciones y actos dictados por el Gobierno de la Nación: a) el Real Decreto 2615/1985, de 4 de diciembre, por el que se aprueba el Reglamento de Entidades de Previsión Social; b) la Orden del Ministerio de Economía y Hacienda, de 9 de abril de 1987, que desarrolla el citado Reglamento; y c) el oficio de la Dirección General de Seguros del mismo Ministerio, de 21 de mayo de 1987, en el que se deniega la remisión a la Generalidad de Cataluña de la documentación presentada en dicha Dirección General por una 
JURISPRUDENCLA

agrupación mutua para su inscripción en el Registro Especial de Mutualidades de Previsión Social. El Estado puede emanar bases para la ordenación de los seguros privados que incidan en las Mutualidades de Previsión Social en la medida en que estas entidades lleven a cabo una actividad aseguradora, y sin que el alcance de esas normas básicas llegue al aspecto organizativo o estructural de las mismas $y$, en su caso, a otras funciones, aspectos que caen dentro de la órbita de las competencias exclusivas autonómicas. En esta labor delimitadora de las bases de la actividad aseguradora, el Reglamento estatal puede completar a la Ley e imponerse como límite a la intervención normativa de las Comunidades con competencias, siempre y cuando no vaya más allá de lo previsto en la Ley previa.

«El Decreto por el que se aprueba el Reglamento de Entidades de Previsión Social es un vehículo normativo idóneo para completar la fijación legal de las bases estatales para la ordenación de los seguros (art. 149.1.11 de la Constitución), que se apliquen a la actividad aseguradora de las Mutualidades de Previsión Social. Porque ya los arts. 18.1, 21 y 39.3 de la Ley 33/1984 que el Decreto viene a completar - y que en su día fueron declarados constitucionales por la STC 86/1989- establecían un sistema de distribución de competencias presidido por las normas básicas establecidas en el Capítulo Cuarto de dicha Ley (arts. 16 a 21), pero cuya "regulación o desarrollo legislativo y reglamentario corresponderá conforme al art. 39 al Estado o a las Comunidades Autónomas en el ejercicio de las competencias que a éstas les estén atribuidas" (art. 21); y la Disposición final 6. ${ }^{a}$ (apartado 2. $)$ habilitaba al Gobierno para desarrollar reglamentariamente los preceptos contenidos en la Ley sobre Mutualidades de Previsión Social "en el ámbito de sus competencias" y en el plazo de un año desde la publicación de la Ley. Por tanto, definido lo básico en una Ley formal, la misma efectuaba una habilitación y permitía un complemento reglamentario por el Estado en la medida indispensable para preservar un tratamiento uniforme...

No es cierto, pues - como pretende el Gobierno Vasco-, que en el citado Capítulo Cuarto de la Ley se agoten todas las posibles bases en la ordenación del sector, ni nada obliga a pensar - antes bien al contrario- que en aquellos escasos artículos de ese Capítulo pueda darse a la actividad aseguradora de las mutualidades un tratamiento uniforme para todo el Estado. Se cumple, además, aquí el principio de preferencia de la Ley en la delimitación de lo básico, y a la vez la intervención complementaria del Reglamento en desarrollo de la Ley en esta tarea se justifica en el carácter marcadamente técnico de la actividad aseguradora, en general, y del mutualismo, en particular. Por otro lado, el pro- 
pio Decreto (art. 9) concreta los preceptos del mismo que deben tener la consideración de normas básicas, evitando un ámbito de inseguridad y confusión incompatible con un sistema de distribución de competencias... Nada puede reprocharse en este supuesto, prima facie, a la previsión de normas básicas de forma complementaria por un Reglamento estatal en desarrollo de Ley y dotado de la conveniente habilitación.

Pero, hecha en principio esta afirmación, resta por ver si los concretos preceptos contenidos en el Decreto exceden del ámbito de la competencia estatal y desbordan la facultad de emanar bases bien por llegar a un grado de desarrollo "que deje vacía de contenido la correlativa competencia" autonómica (STC 1/1982, f. j. 1..$^{\circ}$ ), bien por resultar extraños al objeto del título competencial del Estado previsto en el art. 149.1.11 de la Constitución: ordenación de la actividad aseguradora" (vid. f. j. 4).

Fallo: $10^{\circ}$ Declarar que corresponde a la Comunidad Autónoma del País Vasco y a la Comunidad de Cataluña la competencia de lo establecido en los artículos $15,16,26$, apartados $3 .^{\circ}$ y $4 .^{\circ}$; y 29 , apartado $1 .^{\circ}$, del Real Decreto 2615/1985, de 4 de diciembre y que, por tanto, tales preceptos no son aplicables directamente en el ámbito territorial de dichas Comunidades Autónomas.

2. Declarar que corresponde a las Comunidades Autónomas del País Vasco y de Cataluña la competencia para regular lo establecido en los artículos 1 y 5 de la Orden del Ministerio de Economía y Hacienda de 9 de abril de 1987, dictada en desarrollo del citado Real Decreto y que, por tanto, dichos preceptos no son de aplicación directa en las citadas Comunidades Autónomas.

3. Desestimar el conflicto en todo lo demás.

(Sentencia n. ${ }^{\circ} 220 / 1992$, de 11 de diciembre. BOE 19-1-1993. F. García-Mon y González-Regueral).

\section{C) Leyes de Presupuestos}

1. Recursos de inconstitucionalidad núms. 336/1986 y 349/1986, acumulados, promovidos respectivamente por el Gobierno Vasco y por la Junta de Galicia, contra determinados preceptos de la Ley 46/1985, de 27 de diciembre, de Presupuestos Generales del Estado para 1986. Contenido de las Leyes de Presupuestos. 
«La obligación de incluir en los Presupuestos Generales del Estado la totalidad de los gastos e ingresos en el sector público estatal no impide que, junto a la consignación de las correspondientes partidas, la Ley que apruebe dichos Presupuestos establezca otras disposiciones de carácter general en materias propias de la Ley ordinaria estatal (con excepción de lo dispuesto en el ap. 7 del mismo art. $134 \mathrm{CE}$ ) que guarden directa relación con las previsiones de ingresos y las habilitaciones de gastos de los Presupuestos o con los criterios de política económica general en que se sustentan (SSTC 63/1986, 65/1987 y 65/1990). Muy recientemente, esta concepción ha sido matizada en el sentido de exigir una relación funcional directa de las normas del texto articulado con los estados de ingresos y gastos, como "complemento necesario para la mayor inteligencia y para la mejor y más eficaz ejecución del presupuesto y, en general, de la política económica del Gobierno" (STC 76/1992). Es evidente por sí mismo que la regulación de las remuneraciones de los servidores públicos, aun cuando fragmentaria, con el establecimiento de un límite porcentual máximo para su incremento, guarda la debida conexión con el contenido y la finalidad de la ley presupuestaria, desde el momento que dotan de sustancia a uno de sus capítulos más importantes cualitativa y cuantitativamente, incidiendo en el cuadro económico general. En el mismo caso está la prohibición de financiar con fondos públicos las mutualidades de previsión extravagantes del sistema general de Seguridad Social, por su carácter complementario o sustitutivo de las retribuciones» (vid. f. j. 3).

Fallo: $1 .^{\circ}$ Tener por desistida a la Junta de Galicia de la impugnación del art. 59 de la Ley impugnada.

2. Declarar que el art. 11 de la Ley $46 / 1985$, no es contrario a la Constitución interpretado en los términos del f. j. $3 .^{\circ}$ de esta Sentencia.

3. Declarar que el art. 62.3 de la antedicha Ley tampoco es contrario a la Constitución interpretado en los términos del f. j. 9. ${ }^{\circ}$.

4. Desestimar los recursos en todo lo demás.

(Sentencia $n .^{\circ}$ 237/1992, de 15 de diciembre. BOE 20-1-1993. $R$. de Mendizábal Allende).

\section{ORGANIZACIÓN ADMINISTRATIVA}

1. Recurso de amparo 857/1990 contra el Acuerdo del Pleno del Ayuntamiento de Puerto de la Cruz (Tenerife), de 2 de marzo de 1989, sobre 
composición de las Comisiones Municipales, así como contra las Sentencias de 17 de mayo de 1989 de la Sala de lo Contencioso-Administrativo de la Audiencia Provincial de Santa Cruz de Tenerife y 28 de diciembre de 1989 de la Sala Tercera del Tribunal Supremo.

«La proporcionalidad o las desviaciones de la misma enjuiciables en amparo por devenir constitutivas de una discriminación vedada por el art. 23.2 de la Constitución, no pueden ser entendidas de una forma estrictamente matemática, sino que deben venir anudadas a una situación notablemente desventajosa y a la ausencia de todo criterio objetivo o razonamiento que las justifique».

Fallo: Desestimar el recurso de amparo.

(Sentencia n. ${ }^{\circ}$ 30/1993, de 25 de enero. BOE 24-2-1993. L. López Guerra).

\section{HACIENDAS LOCALES}

1. Cuestiones de inconstitucionalidad acumuladas núm. 1062/1988, formulada por la Sala Primera de lo Contencioso-Administrativo de la Audiencia Territorial de Valencia, sobre supuesta inconstitucionalidad del art. 4 del Real Decreto-Ley 15/1978, de 7 de junio, y núm. 2191/1990, formulada por la Sala de lo Contencioso-Administrativo del Tribunal Superior de Justicia de la Comunidad de Valencia, sobre inconstitucionalidad del art. 355, apartado 5, del Texto Refundido de las Disposiciones legales vigentes en materia de Régimen Local, de 18 de abril de 1986 (TRRL), en relación con el Impuesto Municipal sobre el Incremento del Valor de los Terrenos. El TC tras desestimar la cuestión de inconstitucionalidad 1062/1988 por entender que la argumentación judicial adolece de notoria falta de consistencia, al referirse toda ella a la modalidad ordinaria del impuesto que no era la considerada en el proceso a quo, considera que tampoco debe estimarse la cuestión de inconstitucionalidad 2191/1990, puesto que el artículo 355, apartado 5 del TRRL no es inconstitucional pues no vulnera los principios de capacidad económica, reserva de ley tributaria y autonomía local en materia tributaria.

«La inconstitucionalidad del art. 355.5 TRRL se fundamenta por la Sala proponente en un doble orden de razones. Por un lado, porque dicho precepto, al no asegurar adecuadamente la imposición del incremento real del valor de los terrenos, y excluir "la obligatoriedad del ajuste a la inflación del valor inicial en la medición de la plusvalía", 
determina el gravamen "no sólo de la plusvalía real y efectiva sino también de una plusvalía nominal o ficticia", vulnerando así el principio de capacidad económica del art. $31.1 \mathrm{CE}$, cuyo "pleno respeto exige depurar o separar, excluyéndolo, ese componente ficticio debido a la inflación". Por otro lado, porque tal precepto contiene una habilitación al Gobierno respecto a un elemento esencial del tributo que no respeta el principio de reserva de ley tributaria (arts. 31.3 y $133 \mathrm{CE}$ ); y, además, porque tratándose de un impuesto municipal, desconoce el principio constitucional de autonomía local (arts. 140,142 CE), y su "exigencia de respetar una esfera mínima de propia decisión municipal en materia tributaria» (vid. f. j. 3).

«El citado precepto (art. 355.5 del TRRL) no establece, ciertamente, una corrección automática y obligatoria de los valores iniciales, como la prevista para este impuesto en la Ley de Bases de 1975. Pero de ahí no puede deducirse que vulnere los principios del art. $31.1 \mathrm{CE}$ y, en especial, el de capacidad económica. Ni de este principio puede deducirse la obligatoriedad de practicar, en todo caso, correcciones monetarias, ni éstas tienen por qué articularse, necesariamente, de forma automática mediante la aplicación de un cierto índice con exclusión de otros posibles métodos. Aunque, como ya hemos apuntado, tampoco permite al legislador desconocerlos por completo siempre que la erosión inflacionaria sea de tal grado que haga inexistente o ficticia la capacidad económica gravada por el tributo.

Como ya se ha indicado, el legislador goza en principio de libertad para decidir si aplica o no correcciones monetarias así como para determinar la fórmula concreta de llevarlas a cabo. En este caso concreto, el legislador establece una doble autorización al Gobierno. De una parte, para apreciar cuándo concurren las "razones de política económica" que "exijan" practicar las correcciones. De otra, para determinar cómo deben practicarse las indicadas correcciones En sí mismo considerado, el precepto no incorpora una prohibición de practicar correcciones monetarias, sino que habilita al Gobierno para que determine cuándo y cómo deben practicarse las indicadas correcciones. Ciertamente la autorización al Gobierno está redactada en términos de gran amplitud, aunque ello no significa que el Gobierno goce de una libertad absoluta de hacer uso o no de esta habilitación. Pues no cabe admitir que la remisión a "razones de política económica" excluya el respeto a los principios y valores informadores de un sistema tributario justo que consagra el art. 31.1 CE. Por ello, el no ejercicio de esa autorización por el Gobierno podría dar lugar, en situaciones extremas, a una tributación irracio- 
nal y arbitraria que rebasara los límites constitucionales; pero tal efecto no podría imputarse directamente al precepto ahora cuestionado sino a la inactividad, en su caso, del Gobierno. En consecuencia, y en cuanto articula una técnica que posibilita tener en cuenta los efectos que la elevación del nivel general de precios pueda tener sobre la base imponible del impuesto, puede considerarse que el referido precepto no viola el principio de capacidad económica y es, por tanto, conforme a la $\mathrm{CE}$ » (vid. f. j. 6).

«En la medida en que la aplicación de las correcciones monetarias se justifica en atención a las fluctuaciones del nivel de precios, es razonable que la Ley autorice al Gobierno para que éste aprecie cuándo concurren las circunstancias que justifican la práctica de las expresadas correcciones. Y es de observar, asimismo, que la heterogeneidad de los elementos intervinientes en este impuesto y lo imprevisible de su evolución en el tiempo determinan que el grado de concesión aquí exigible no puede equiparse al requerido con relación a otros elementos configuradores de la base, por lo que ningún reproche cabe hacer desde la perspectiva del principio de reserva de ley» (vid. f. j. 7).

«La autonomía local, en su proyección en el terreno tributario, no exige que esta intervención, que debe reconocerse a las entidades locales, se extienda a todos y cada uno de los elementos integrantes del tributo. Con relación a la concreta materia cuestionada, la práctica de correcciones monetarias, la autorización al Gobierno no carece de justificación; la complejidad en la elaboración de los posibles índices, la necesidad de asegurar que tales índices sean homogéneos en todo el territorio, así como la incidencia que tales correcciones puedan tener sobre la política económica, justifican plenamente que el legislador haya atribuido dicha facultad al Gobierno. Debe rechazarse, en consecuencia, que la autorización al Gobierno establecida por el citado art. 355.5 vulnere la autonomía local constitucionalmente garantizada» (vid. f.j. 8).

Fallo: $1 .^{\circ}$ Desestimar la cuestión de inconstitucionalidad 1062/1988 sin entrar en el fondo del asunto.

2. Declarar que no es inconstitucional el art. 355.5 del TRRL.

(Sentencia n. ${ }^{\circ} 221 / 1992$, de 11 de diciembre. BOE 19-1-1993. J. D. González Campos. Voto particular que formula. A. Rodríguez Bereijo, y al que se adhiere J. Gabaldón López). 
JURISPRUDENCIA

\section{EMPLEO PÚBLICO}

1. Conflicto de competencia 1256/1987 promovido por el Gobierno de la Nación, frente al Gobierno de la Comunidad Autónoma de Canarias, en relación con la disposición transitoria del Decreto 38/1987, de 7 de abril, por el que se modifica el Reglamento de Organización y Funcionamiento del Consejo Consultivo de Canarias. El TC entiende que la norma impugnada vulnera la legislación básica estatal (art. 19.1 de la Ley 30/84) que elimina las convocatorias o turnos restringidos, que, como regla general, no podrán ser utilizados por las Administraciones autonómicas para la selección de su personal funcionarial.

"La norma controvertida prevé, pues, unas pruebas restringidas para el acceso a la condición funcionarial en el Consejo Consultivo de Canarias que quedan circunscritas a aquellos que hubieren sido seleccionados para ocupar provisionalmente plazas de funcionarios en el Consejo y estuvieren prestando sus servicios al mismo. Es precisamente ese carácter restringido el que motiva la impugnación del Estado, por cuanto, entre otras razones y en lo que principalmente interesa, contradice lo dispuesto en el art. 19.1 de la Ley 30/1984, de 2 de agosto, de Medidas para la Reforma de la Función Publica, que, con el carácter de básico, dictado al amparo de la competencia que al Estado le atribuye el art. 149.1.18. ${ }^{a}$ de la Constitución, prohíbe dichas pruebas restringidas, sin que, de otra parte, la excepción que ha previsto la disposición transitoria sexta, 4, de la misma Ley 30/1984, de 2 de agosto, pueda llegar a dar cobertura a la norma autonómica impugnada, dado que la excepción ha quedado circunscrita por la necesaria concurrencia de unos requisitos que no concurren en la referida norma autonómica.

Planteada la controversia en la forma expuesta, es claro que la premisa de la que arranca la argumentación del Abogado del Estado resulta correcta. En efecto, en la STC 151/1992, f. j. $3 .^{\circ}$, ya hemos concluido que el art. 19.1 de la Ley 30/1984, de 2 de agosto, define como elemento básico de la regulación de las Administraciones Públicas la eliminación de las llamadas convocatorias o turnos restringidos, las cuales, como regla general, no podrán ser puestas en práctica por las Administraciones autonómicas para la selección de su personal funcionarial. Por ello, de acuerdo con el referido art. 19.1, el acceso a la función pública ha de articularse a través de convocatorias públicas o abiertas, a no ser que concurran las circunstancias a las que el propio Legislador estatal ha condicionado la posibilidad de que las Comunidades Autónomas puedan excepcionalmente realizar convocatorias en turnos restringidos para quienes, no ostentando la condición de funcionarios de carrera, 
prestan ya, sin embargo servicios en sus correspondientes Administraciones. Tal es, en concreto, el caso de la disposición transitoria sexta, $4^{\circ}{ }^{\circ}$ de la Ley 30/1984, de 2 de agosto, que prevé una excepción a la regla general del art. 19.1 de la misma Ley, al permitir que los Consejos de Gobierno de las Comunidades Autónomas puedan convocar restringidamente pruebas específicas de acceso a la función pública» (vid. f. j. 2).

«La norma básica de excepción - la disposición transitoria sexta, 4. de la Ley 30/1984, de 2 de agosto-, queda delimitada por la necesaria concurrencia de dos requisitos fundamentales. Uno de carácter personal, consistente en que la pruebas restringidas se dirijan a quienes tuviesen la condición de "contratados administrativos" en expectativa de acceso a su respectiva función pública. Y un segundo, de carácter temporal, que limita esa posibilidad a aquellos que hubieran sido contratados mediante convocatorias públicas con anterioridad al 15 de marzo de 1984. Pues bien, en la norma autonómica objeto del conflicto no concurren simultáneamente los requisitos señalados, lo que justifica la conclusión ya anticipada» (vid. f. j. 3).

Fallo: La disposición transitoria del Decreto del Gobierno de Canarias 38/1987, de 7 de abril, es contraria al orden constitucional de competencias $y$, por consiguiente, se declara nula.

(Sentencia n. ${ }^{\circ} 4 / 1993$, de 14 de enero. BOE 12-2-1993. A. Rodríguez Bereijo).

\section{CARGOS PÚBLICOS}

1. Recurso de amparo 946/1989 interpuesto por un Diputado de la Asamblea Regional de Murcia y Portavoz del Grupo Parlamentario Popular, contra al Acuerdo de la Mesa de la Asamblea Regional de Murcia de 31 de marzo de 1989, que denegó la tramitación de una interpelación sobre la asistencia sanitaria en Murcia. A juicio del TC no se produce un vulneración del derecho al acceso igualitario a las funciones y cargos públicos y al ejercicio de los mismos sin perturbaciones ilegítimas.

«Es evidente el carácter específico de las interpelaciones según las entiende el Reglamento de la Asamblea Regional de Murcia, que han de tener como tema aspectos o realizaciones concretas de su Consejo de Gobierno o de cualquiera de sus Departamentos. La que fue rechazada y nos ocupa ahora tiene por marco la asistencia sanitaria en Murcia, 
SURISPRUDENCIA

cuya supuesta degradación se denuncia, como también la falta de voluntad política para remediarla y en consecuencia se pide en ella que "el Gobierno explique las razones de su actuación" en esa materia, así como "las medidas adoptadas para que esta bochornosa situación no se vuelva a repetir". La lectura desapasionada del texto pone de manifiesto por sí misma su talante global o genérico. En tal característica funda la Mesa el rechazo, con la sugerencia de que para la finalidad pretendida utilice los procedimientos parlamentarios adecuados, como pueden ser el debate general o monográfico y la sesión informativa, tal y como aparecen configurados reglamentariamente (arts. 134 y 136). Por todo ello, la Mesa no ha desconocido ni menoscabado el derecho fundamental invocado cuyo ejercicio en este caso ha de acomodarse "a los términos que el reglamento determine" (art. 25.3 EAM), por exigencia de su configuración constitucional» (vid. f. j. 4).

Fallo: Desestimar el presente recurso de amparo.

(Sentencia $n .^{\circ}$ 225/1992, de 14 de diciembre. BOE 19-1-1993. R. de Mendizábal Allende).

\section{RÉGIMEN ELECTORAL}

1. Recurso de amaro electoral $3143 / 1992$ promovido por el PSOE de Badajoz contra Sentencia de la Sala de lo Contencioso-Administrativo del Tribunal Superior de Justicia de Extremadura, de 26 de noviembre de 1992, desestimatoria del recurso contencioso-electoral 1008/1992, promovido contra el Acuerdo de la Junta Electoral Central de 18 de septiembre de 1992, sobre expedición de credencial de Alcalde Pedáneo de la Entidad Local Menor de Valdivia, municipio de Villanueva de la Serena (Badajoz). Se discute la sustitución de quien fue elegido Alcalde Pedáneo de Valdivia, como consecuencia de su fallecimiento, considerándose adecuada la aplicación analógica del art. 184.f) de la LOREG.

"Así planteados los términos del presente debate es obvio que el mismo excede del ámbito propio del recurso de amparo, conforme al art. 41 LOTC, en relación con el art. 53.2 CE, pues la discusión gira en torno a la selección o determinación de la norma aplicable para verificar la sustitución, a su fallecimiento, del Alcalde Pedáneo elegido en anterior proceso electoral o, si se quiere, dicho en otros términos, sobre la adecuación de la norma legal para el acceso a un cargo público (art. 23.2); acceso que trae causa pero no es el resultado de un 
proceso electoral. Lo que nos sitúa ante una cuestión que pertenece exclusivamente al ámbito de la jurisdicción ordinaria, sin perjuicio de que este Tribunal pueda revisar el juicio realizado por los órganos jurisdiccionales si la resolución recurrida fuera inmotivada, irrazonable o arbitraria.

Ahora bien, ello no ocurre en el caso de la Sentencia del Tribunal Superior de Justicia de Extremadura aquí recurrida; pues con independencia de que la solución propuesta por el recurrente no sea jurídicamente insostenible, no es menos cierto, sin embargo, que la adoptada en las resoluciones ahora impugnadas es igualmente defendible en términos constitucionales. En efecto, del hecho de que los electores de la Pedanía de Valdivia se hayan pronunciado en su día entre la pluralidad de candidaturas puede perfectamente deducirse, como han hecho la Junta Electoral Central y el Tribunal Superior de Justicia, que la previsión normativa más adecuada al caso es la establecida en el art. $184 \mathrm{f}$ ) de la Ley Electoral, por contenerse en este precepto una regulación ideada para supuestos que guardan una evidente identidad de razón con el ahora analizado. Si existe un mecanismo pensado para la sustitución de electos cuando en las correspondientes elecciones han concurrido diversas candidaturas, es razonable servirse de él cuando la misma circunstancia se presenta en supuestos en los que, dándose igualmente el hecho de la pluralidad de candidatos, no existe, sin embargo, una previsión normativa específica» (vid. f. j. 2).

Fallo: Desestimar el presente recurso de amparo.

(Sentencia n. ${ }^{\circ}$ 1/1993, de 13 de enero. BOE 12-2-1993. J. D. González Campos).

2. Recurso de amparo electoral 3208/1992 formulado por el PP contra la Sentencia de 18 de diciembre de 1992, de la Sala de lo ContenciosoAdministrativo del Tribunal Superior de Justicia de Canarias, recaída en el recurso contencioso-electoral 979/1992, interpuesto contra el Acuerdo de proclamación y elección de Alcalde adoptado por el Pleno del Ayuntamiento de Las Palmas de Gran Canaria el 14 de noviembre de 1992. Se discute la condición de "cabeza de lista" de un llamado "Grupo Mixto" de un Concejal, designado candidato y posteriormente elegido Alcalde, que había comparecido en tal condición en la candidatura del PP, pero que posteriormente, y por su propia voluntad, se habia dado de baja de dicho partido, y había constituido con otros Concejales un grupo municipal propio, llamado "Grupo Mixto». 
JURISPRUDENCLA

«No se trata aquí de un problema de una renuncia a la condición de cabeza de lista, sino de la pérdida de tal condición por dejar de pertenecer a la lista y grupo en que participó en las elecciones. Si se admite, y así lo hace la Sentencia, que ya no se es cabeza de esa lista, de ello se deriva necesariamente que se ha perdido tal condición, como resultado de su propia y legítima decisión de abandonar el grupo. Por ello, la proclamación como candidato de una cabeza de lista del Grupo Mixto, resulta incompatible con las exigencias que establece el art. 196,a) LOREG en relación con el art. 44 de la misma, puesto que tal Grupo Mixto no puede ser considerado como una lista electoral.

En consecuencia, el Concejal proclamado candidato "por el Grupo Mixto", y posteriormente elegido como Alcalde, en el momento de su proclamación como Alcalde, no pudo ser considerado como cabeza de su correspondiente lista, a efectos del art. 196,a) LOREG, por lo que tal designación y elección han infringido dicho precepto, lo que implica que una y otra no se han realizado "con los requisitos que señalan las leyes", con la consecuente vulneración del derecho reconocido en el art. $23.2 \mathrm{CE}$ ( vid. f. j. 3).

Fallo: Estimar el recurso de amparo y, en consecuencia:

1. Anular la Sentencia impugnada y los Acuerdos de proclamación de candidatos y elección de Alcalde del Pleno del Ayuntamiento de Las Palmas de Gran Canaria de 4 de noviembre de 1992.

2. $\quad$ Reconocer el derecho del recurrente a la adopción de un nuevo Acuerdo del Pleno del Ayuntamiento de Las Palmas de Gran Canaria en el que se proclamen candidatos a aquellos Concejales que en el momento de la elección de Alcalde ostenten la condición de "cabeza de lista" de la candidatura por la que fueron elegidos, procediendo, entre ellos, a la elección de Alcalde.

(Sentencia n. ${ }^{\circ} 31 / 1993$, de 26 de enero. BOE 24-2-1993. M. Rodríguez Piñero y Bravo-Ferrer).

\section{ACTOS ADMINISTRATIVOS. EJECUTIVIDAD}

1. Cuestión de inconstitucionalidad 1445/1987 promovida por la Sala de lo Contencioso-Administrativo de la Audiencia Territorial de Cáceres, en relación con el artículo 6.2 de la Ley 34/1979, de 16 de noviembre, de Fincas Manifiestamente Mejorables. El TC entiende que el 
inciso según el cual «no obstante, no se suspenderá en ningún caso la ejecución del Decreto impugnado" es inconstitucional, puesto que al impedir la suspensión del Decreto 38/1987 de la Junta de Extremadura por el que declaró manifiestamente mejorable una finca, conculca lo dispuesto en los arts. 24 y 106.1 de la Constitución.

«Reconocida por ley la ejecutividad de los actos administrativos, no puede el mismo legislador eliminar de manera absoluta la posibilidad de adoptar medidas cautelares dirigidas a asegurar la efectividad de la Sentencia estimatoria que pudiera dictarse en el proceso contencioso-administrativo; pues con ello se vendría a privar a los justiciables de una garantía que, por equilibrar y ponderar la incidencia de aquellas prerrogativas, se configura como contenido del derecho a la tutela judicial efectiva. Para que ésta se considere satisfecha, es, pues, preciso que se facilite que la ejecutividad pueda ser sometida a la decisión de un Tribunal, y que éste, con la información y contradicción que resulte menester, pueda resolver sobre su eventual suspensión (STC 66/1984, f. j. 3..$^{\circ}$ ). Ello, desde luego, sin perjuicio del margen de discrecionalidad del legislador para modular o condicionar la concesión de esa suspensión y del margen de apreciación del juzgador para conceder o negar, ponderadas las circunstancias del caso, la suspensión pedida (STC 66/1984, f. j. 3. ')" (vid. f. j. 3).

«La prerrogativa de la ejecutividad no puede desplegarse libre de todo control jurisdiccional y debe el legislador, por ello, articular, en uso de su libertad de configuración, las medidas cautelares que hagan posible el control que la Constitución exige. Al haberlas suprimido aquí por entero se ha venido también a desconocer, en definitiva, el mandato de plena justiciabilidad del actuar administrativo presente en el art. 106.1» (vid. f. j. 6).

Fallo: Declarar inconstitucional y, por consiguiente, nulo el inciso «No obstante, no se suspenderá en ningún caso la ejecución del Decreto impugnado» del art. 6.2 de la Ley impugnada.

(Sentencia $n{ }^{\circ}$ 238/1992, de 17 de diciembre. BOE 20-1-1993. L. López Guerra).

\section{POLICIA}

\section{a) Policías locales}

1. Recurso de inconstitucionalidad 1753/1988 interpuesto por el Presidente del Gobierno, contra la Ley de la CA de la Región de Murcia 
JURISPRUDENCIA

5/1988, de 11 de julio, de Coordinación de Policías Locales. El TC declara inconstitucional la habilitación que la Ley autonómica hace a las entidades locales supramunicipales para crear su cuerpo de policía propio.

«Aun cuando el art. 2 de la Ley Orgánica 2/1986 vincule a las policías locales a las Corporaciones homónimas, invocadas genéricamente, es evidente que aquella expresión, utilizada también como rúbrica del Título V, se reduce en su contenido al ámbito del municipio y sólo a él (art. 51). La coordinación, a la que luego habrá ocasión de aludir y "las demás facultades" en relación con ellas constitucionalmente tienen como titular a las Comunidades Autónomas y como destinatarios únicos a los Ayuntamientos, según la Ley estatal marco, como pone de manifiesto su lectura. Entre estas facultades que pueden ser legislativas para adecuar el régimen estatutario general de los agentes a las peculiaridades de cada Administración Territorial o la posibilidad de exigir la colaboración con la policía autonómica (arts. 51, 52.1 y 53.1 h), no se contempla la competencia para autorizar la creación de otros cuerpos distintos de los municipales" (vid. f. j. 1..$^{\circ}$ ).

Fallo: 1. Estimar parcialmente el recurso y, en consecuencia, declarar la inconstitucionalidad y nulidad del art. 3.2 de la Ley impugnada.

2. Desestimar el recurso en todo lo demás.

(Sentencia $n .^{\circ}$ 25/1993, de 21 de enero. BOE 24-2-1993. R. de Mendizábal Allende).

2. Recurso de inconstitucionalidad promovido por el Presidente del Gobierno contra el art. 3 y la disposición adicional primera de la Ley de la CA de las Islas Baleares 10/1988, de 26 de octubre, de coordinación de Policías Locales. El TC estima el recurso y declara la inconstitucionalidad del art. 3 , en su último inciso, donde se indica "o en las urgencias, sin perjuicio de la inmediata comunicación a la citada autoridad", así como de la Disposición Adicional primera de la Ley, que establece la posibilidad de constituir mancomunidades intermunicipales para la prestación en común de los servicios de Policía Local.

«Examinando el modo en que la LOFCS ha delimitado la competencia enunciada en el art. 148.1.22 CE... es de observar que esta compe- 
tencia, como se dice en la STC 25/1993, no comprende facultad alguna para crear o autorizar la creación de Cuerpos de Policía supramunicipales; y aunque la disposición impugnada no habla de la creación de Cuerpos sino sólo de la prestación en común de servicios de Policía Local, se ha de llegar a la misma conclusión: la de que la Ley Autonómica se ha excedido en las competencias que la LOFCS le permite.

Ello es así, porque en dicha Ley Orgánica no se contemplan otros Cuerpos de Policía Local que los propios de los municipios (art. 51)... Además la propia LOFCS prohíbe la actuación supramunicipal de la Policía Local, salvo en los supuestos excepcionales y con las condiciones y requisitos que la misma permite, que no pueden extenderse a una prestación en común unificada de servicios de Policía Local fuera de los límites del respectivo municipio (art. 51.3 de la LOFCS), que es lo que trata de autorizar la Disposición adicional impugnada» (vid. f. j. 4..$^{\circ}$ ).

Fallo: Estimar en su totalidad el recurso y, en consecuencia declarar la inconstitucionalidad y nulidad del art. 3, en su último inciso, y de la Disposición adicional primera de la Ley impugnada.

(Sentencia $n .^{\circ} 49 / 1993$, de 11 de febrero, BOE 11-3-1993. F. GarcíaMon y González-Reguera).

3. Recurso de inconstitucionalidad promovido por el Presidente del Gobinerno contra el art. 3.1 i) Ley del Principado de Asturias, 6/1988, de 5 de diciembre, de coordinación de Policías Locales. El TC estima el recurso y declara la inconstitucionalidad del precepto mencionado, que faculta a la CA para fomentar y favorecer los servicios de policía intermunicipal o comarcal donde los Ayuntamientos no puedan sostener una policía propia o donde las circunstancias aconsejen mancomunar o unificar los servicios de Policía Municipal.

El TC se manifiesta en términos similares a la STC $49 / 1993$ (vid. supra). En este sentido señala como «la competencia autonómica excluye la posibilidad de crear Cuerpos de Policía local en régimen de colaboración intermunicipal» (vid. f. j. $3^{\circ}$ ).

Fallo: Estimar el recurso y, en consecuencia declarar la inconstitucionalidad y nulidad del ap. i) del art. 3.1 de la Ley impugnada.

(Sentencia n. ${ }^{\circ}$ 50/1993, de 11 de febrero. BOE 11-3-1993. F. GarcíaMon y González-Regueral). 
JURISPRUDENCLA

4. Recurso de inconstitucionalidad promovido por el Presidente del Gobierno contra los arts. $3 .^{\circ}$ ap. $1 ; 7 .^{\circ}$ ap. 8 y la Disposición adicional primera de la Ley 1/1990, de 26 de abril, de coordinación de Policias Locales de Extremadura. El TC estima parcialmente el recurso y declara la inconstitucionalidad del inciso "y mancomunidades", del art. 3.1 de la Ley impugnada.

«La regulación autonómica desborda, pues, el ámbito de su competencia al aplicarla a un supuesto no autorizado en la Ley Orgánica, que en este punto completa el mandato constitucional y no permite entender que la Ley recurrida se encuentre habilitada para facultar la creación por las mancomunidades de municipios de sus propios Cuerpos de Policía” (vid. f. j. 3..$^{\circ}$.

Fallo: $10^{\circ}$ Estimar parcialmente el recurso y, en consecuencia declarar la inconstitucionalidad y nulidad del inciso "y mancomunidades» del art. 3. ap. $1 .^{\circ}$ de la Ley impugnada.

2. $\quad$ Desestimar el recurso en todo lo demás.

(Sentencia $n .{ }^{\circ} 51 / 1993$, de 11 de febrero. BOE 11-3-1993. J. Gabaldón López).

5. Recurso de inconstitucionalidad promovido por el Presidente del Gobierno contra los arts. 25 ap. 4; 26; 27, letras b) y c); 28 y 29, párr. $3 .^{\circ}$ de la Ley de la Comunidad de Madrid 4/1992, de 8 de julio, de coordinación de Policias Locales. El TC estima parcialmente el recurso y declara la inconstitucionalidad del art. 25.4 en su inciso "e informar la creación de Cuerpos de Policía Local de carácter supramunicipal", el art. 26 y el párrafo $3 .^{\circ}$ del art. 29 de la Ley impugnada.

«El art. 26.1 de la Ley recurrida establece que "los Municipios podrán constituir con otros, mediante el ejercicio del derecho asociativo, mancomunidades para la creación de un Cuerpo de Policía Local propio", prescripción desarrollada por los restantes párrafos del mismo artículo y el inciso impugnado del 25, lo cual, lejos de fundarse en facultad alguna que pueda deducirse del texto de la Ley Orgánica citada, contraviene los términos de la misma, que no permiten inferir esa posibilidad. La regulación autonómica desborda, pues, el ámbito de su competencia al aplicarla a un supuesto no autorizado en la Ley Orgánica, que en este punto complementa el mandato constitucional, porque la competencia exclusiva que el Estatuto propio concede a la Comuni- 
dad de Madrid con el mismo enunciado del precepto constitucional, determina también que sea en los términos de "una ley orgánica", y la del Cuerpo de Seguridad del Estado limita como antes dijimos la facultad de creación de Policías Locales a los Municipios» (vid. f. j. 4).

«Finalmente, se impugna el art. 29, párr. $3 .^{\circ}$ de la Ley, que establece que la Comunidad de Madrid, a través de la Consejería competente en la materia, participe en las Juntas Locales de Seguridad que celebren los municipios (...) La Comunidad de Madrid, que evidentemente tiene competencia para coordinar la actuación de las Policías (art. 27.9 de su EA), no la tiene para regular la composición de la Junta Local de Seguridad, cuya estructura orgánica, en términos generales, se funda en lo dispuesto en el art. 54.2 de la LOFCS. Es concluyente, pues, que no corresponde al precepto impugnado la competencia para regular la composición de dicha Junta ni por tanto para determinar su propia participación en la misma. El párr. 3 del art. 29 de la Ley madrileña debe, pues, declararse inconstitucional» (vid. f. j. 7).

Fallo: 1. ${ }^{\circ}$ Estimar parcialmente el recurso y, en consecuencia declarar inconstitucionales y, por tanto, nulos el art. 25.4, en su inciso "e informar la creación de Cuerpos de Policía Local de carácter supramunicipal", el art. 26 y el párr. $3 .^{\circ}$ del art. 29 de la Ley impugnada.

2. Desestimar el recurso en todo lo demás.

(Sentencia n. ${ }^{\circ}$ 52/1993, de 11 de febrero. BOE 11-3-1993. J. Gabaldón López).

\section{B) Agentes Rurales}

1. Conflicto de competencia 136/1989 planteado por el Gobierno de la Nación en relación con el inciso "cuando estén en acto de servicio llevarán obligatoriamente el arma que corresponda" del art. 11 del Reglamento del Cuerpo de Agentes Rurales de la Generalidad de Cataluña, en la redacción dada a este precepto por el Decreto 381/1988, de 12 de diciembre, del Consejo Ejecutivo de la Generalidad de Cataluña. El TC declara que este inciso no invade las competencias estatales sobre seguridad pública y Fuerzas y Cuerpos de Seguridad.

«Se trata, por otro lado, de un cuerpo de policía administrativo especial (el de los Agentes Rurales), reorganizado por la Generalidad tras 
JURISPRUDENCIA

haberle sido transferido el correspondiente servicio por la Administración del Estado, y cuya regulación tiene como fundamento competencial diversos preceptos estatutarios citados por la representación demandada, que atribuyen a la CA competencias sobre los ámbitos que han de ser objeto de protección y vigilancia por este cuerpo de funcionarios (arts. 9.10, 9.17 y 12.1.4 del EAC)...

La sola mención, en el art. 11, al "arma" que deberán portar los Agentes Rurales y, en relación con ello, a la normativa reguladora de tal "armamento" no convierte al correspondiente cuerpo en un cuerpo de policía general o de seguridad, conclusión que no se compadece ni con las funciones asignadas a este Cuerpo ni con las desarrolladas por el de Guardería Forestal del Estado, objeto, en su día, de transferencia a la Comunidad Autónoma (ap. D. 2 del anexo del RD 1950/1980).

Ha de tenerse en cuenta que la norma autonómica nada innova al respecto, pues al inciso cuestionado sigue un párrafo que establece que "en cuanto al armamento", el Cuerpo de Agentes Rurales se rige por la normativa vigente en la materia", normativa vigente que no puede ser otra que la establecida por el propio Estado, que es al que corresponde en exclusiva la decisión última sobre la tenencia y el uso de armas (art. 149.1.26 CE)» (vid. f. j. 3).

Fallo: Declarar que el inciso impugnado no invade competencia alguna del Estado.

(Sentencia n. ${ }^{\circ} 32 / 1993$, de 1 de febrero. BOE 24-2-1993. M. RodríguezPiñero y Bravo-Ferrer).

\section{DERECHO PÚBLICO DE LA ECONOMta}

\section{A) Entidades de crédito y Cajas de Ahorro}

1. Recurso de inconstitucionalidad 45/1989 interpuesto por 50 Diputados del Congreso contra los arts. 5.1.c) y 12.d) de la Ley 7/1988, de 6 de octubre, de la Asamblea Regional de Murcia, sobre Organos Rectores de las Cajas de Ahorro de la Región de Murcia. El TC considera constitucional la composición de los órganos rectores que establece la Ley impugnada en relación con los porcentajes que ésta atribuye a los representantes de las personas o entidades fundadoras de las mismas $y$ de las Corporaciones municipales. 
«Lo que se impugna es, estrictamente, el art. 5.1.c) de la Ley de la Asamblea Regional de Murcia 7/1988, que viene a reservar el 35\% de los representantes en los órganos de gobierno de las Cajas de Ahorro de la Región a las personas o entidades fundadoras de las mismas, si bien éstas pueden asignar una parte no mayoritaria de ese porcentaje a ciertas instituciones sociales, así como el art. 12.d) de la misma Ley que, en relación con el $40 \%$ de representación en los citados órganos que se reserva a las Corporaciones municipales, prescribe que ninguna de ellas dispondrá de un número de Consejeros Generales de las Cajas superior al $20 \%$ de aquel cupo de representación" (vid. f. j. 2).

«Aplicando esta doctrina general al art. 5.1.c) de la Ley 7/1988 de la Asamblea Regional de Murcia, es claro que tal precepto no vulnera el principio de interdicción de la arbitrariedad de los poderes públicos. Primero, porque no genera ninguna discriminación constitucionalmente inaceptable, pues, aunque es cierto que establece una desigualdad con los llamados a participar en los órganos rectores de las Cajas de Ahorro en otras Comunidades Autónomas, dicha desigualdad se justifica precisamente por la autonomía del legislador regional, que puede extenderse a regular de la manera que considere más conveniente para su Comunidad los porcentajes de participación de los distintos grupos básicos de representación, tal y como declaramos en SSTC 48/1988 y $49 / 1988$, sin afectar por ello a las posiciones jurídicas fundamentales de todos los ciudadanos. En segundo término, porque no puede decirse que la opción del legislador murciano carezca de fundamento desde el punto de vista de la finalidad de democratización de las Cajas de Ahorro que le impone la normativa básica. Así, lo cierto es que ni atribuye a un solo grupo de representación una situación de predominio frente a los demás, ni priva al grupo de impositores de una presencia significativa, aunque minoritaria, ni deja de tener explicación desde aquella óptica democratizadora y participativa que se incremente la representación de las Entidades fundadoras, máxime cuando, como los recurrentes apuntan, se está pensando en una Entidad que tiene su propia legitimación democrática. En realidad, lo que los recurrentes discuten es la proporcionalidad de los porcentajes de participación asignados a cada grupo. Pero, como dijéramos a este respecto en STC 49/1988, "entrar en un enjuiciamiento de cuál sería su medida justa supone discutir una opción tomada por el legislador que, aunque pueda ser discutible, no resulta arbitraria ni irracional".

Lo mismo puede decirse de lo dispuesto en el art. 12.d) de la Ley recurrida. La limitación del porcentaje de representación, que dentro del grupo "Corporaciones municipales", puede corresponder a un solo 
JURISPRUDENCLA

Ayuntamiento a un máximo del $20 \%$ no carece de fundamento, desde el punto de vista de la finalidad democratizadora que debe presidir la regulación legal, pues ni esta finalidad impone una representación de cada Corporación estrictamente proporcional al número de oficinas, al de impositores o al volumen de depósitos que la Caja de Ahorros correspondiente tenga o capte en su término municipal, ni puede considerarse ilegítima la opción del legislador favorable a asegurar la participación de un mayor número de Corporaciones municipales, sin que deba este Tribunal enjuiciar si el límite porcentual fijado es o no el más acertado o el más adecuado a la finalidad perseguida" (vid. f. j. 5).

Fallo: Desestimar el recurso de inconstitucionalidad.

(Sentencia n. ${ }^{\circ}$ 239/1992, de 17 de diciembre. BOE 20-1-1993. M. Rodríguez-Piñero y Bravo-Ferrer).

2. Recurso de inconstitucionalidad 1762/1989 y conflicto positivo de competencia 2415/1989 (acumulados), promovido el primero por el Presidente del Gobierno contra el art. 1 de la Ley del Parlamento de Cataluña 6/1989, de 25 de mayo, en cuanto añade un párrafo cuarto al apartado b) del art. 17 de la Ley del Parlamento de Cataluña 15/1985, de regulación de las Cajas de Ahorros; y planteado el segundo por el Gobierno de la Nación contra el art. 18.2 de las normas reguladoras de los procedimientos de designación, convocatoria y funcionamiento de los órganos de gobierno de las Cajas de Ahorro, aprobadas por Decreto del Consejo Ejecutivo de la Generalidad de Cataluña 190/1989, de 1 de agosto. La exigencia a las Corporaciones Locales de una mayoría de dos tercios para designar los Consejeros Generales de la Caja que le corresponde nombrar, vulnera la norma básica contenida en el art. 47.2 de la LRBRL.

"Los presentes recursos de inconstitucionalidad y conflicto positivo de competencia acumulados tienen por objeto la impugnación de los preceptos, uno de rango legal y otro de rango reglamentario, de idéntico contenido. Ambos exigen el voto favorable de las dos terceras partes del número de hecho de miembros de la Corporación Local fundadora de una Caja de Ahorros, en ningún caso inferior a la mayoría absoluta del número legal de esos miembros, para la designación de los consejeros generales de la Caja que le corresponde nombrar. Y ambos son impugnados por el mismo motivo, esto es, sustancialmente, por infringir el precepto de carácter básico contenido en el art. 47.2 de la LBRL, que no prevé ese supuesto entre aquéllos para los que se impone la citada mayoría cualificada». (vid. f. j. 1. ${ }^{\circ}$ ). 
«El legislador estatal ha considerado básico el régimen de mayoría relativa en la adopción de acuerdos, como regla general, pero ha dejado al legislador de desarrollo (art. 47.3.m) la posibilidad de ampliar el número de supuestos en los que la mayoría simple puede ser sustituida por mayoría absoluta, por lo que el legislador autonómico podría disponer la exigencia de mayoría absoluta para determinados acuerdos. Otro es el caso de la mayoría de dos tercios que el art. 47.2 LBRL requiere para cuatro supuestos muy singularizados (...) El listado de supuestos incluido en el art. 47.2 LBRL es cerrado y exhaustivo, lo que se deduce no sólo de sus propios términos, sino también de la especial gravedad y trascendencia de los Acuerdos, que explica la exigencia de una mayoría reforzada. Es claro que esta forma de alteración de la regla general ha sido establecida por el legislador de las bases con carácter rigurosamente excepcional. De ello cabe inferir que el art. 47.2 no es sólo un límite negativo, que impida al legislador autonómico fijar una mayoría distinta para tales supuestos, sino que constituye también un límite positivo por definir taxativamente los casos en los que excepcionalmente se exige la mayoría de dos tercios de hecho de los miembros de la Corporación (...) En consecuencia, la fijación por el legislador catalán ( $\mathrm{y}$, conforme al mismo, por el Consejo Ejecutivo de la Generalidad) de un nuevo supuesto para el que se exige la referida mayoría cualificada, vulnera la norma básica contenida en el art. 47.2 de la LBRL, lo que conlleva la nulidad de los preceptos que lo infringen" (vid. f. j. 3. ${ }^{\circ}$ ).

Fallo: Estimar el recurso de inconstitucionalidad y el conflicto de competencia, y declarar inconstitucionales y nulos los preceptos impugnados, así como que la competencia controvertida corresponde al Estado.

(Sentencia n. ${ }^{\circ} 33 / 1993$, de 1 de febrero. BOE 24-2-1993. M. RodríguezPiñero y Bravo-Ferrer).

3. Recursos de inconstitucionalidad 1518/1990 y 432/1992, acumulados y promovidos por el Presidente del Gobierno, de una parte, contra los arts. 7.1b) y, por conexión con el mismo, el último inciso del art. 21.2 y el último inciso del primer párrafo del art. 29.2; 15.3; 29.2, segundo párrafo, y Dispos. Transit. $7^{a}$ de la Ley de la Asamblea Regional de Cantabria 1/1990, de 12 de marzo, por la que se regulan los órganos rectores de las Cajas de Ahorro con sede social en la CA de Cantabria; $y$, por otro lado, contra la Dispos. Transit. $1 .{ }^{a}, n^{\circ}{ }^{\circ} 2$, de la Ley 8/1991, de 28 de noviembre, de la Asamblea Regional de Cantabria, por la que 
JURISPRUDENCIA

se modifica la Ley de Cantabria 1/1990. El TC declara inconstitucionales y nulos los arts. 15.3 y 29.2, párr. $2 .^{\circ}$ de la Ley $1 / 1990$.

«El art. 15.3 de la Ley cántabra establece que "en el caso de no existir, desconocerse o haber desaparecido las personas o Entidades fundadoras, su representación será repartida entre los grupos definidos en los aps. a) y b) del art. 7.1, de acuerdo con los porcentajes establecidos en el mismo e incrementándolos proporcionalmente".

La previsión contradice frontalmente lo dispuesto en el art. 2.3, párrafo $3 .^{a}$ de la LORCA (Ley 31/1985, de 2 de agosto, de regulación de las normas básicas sobre órganos rectores de las Cajas de Ahorro), en virtud del cual "en el supuesto de las Cajas de Ahorro cuyas personas o Entidades fundadoras no estén identificadas en sus Estatutos a la entrada en vigor de la presente Ley, o bien estándolo no puedan o no deseen ejercitar la representación correspondiente a las mismas, ésta se repartirá proporcionalmente entre los restantes grupos".

El carácter básico de esta previsión no ha sido en momento alguno cuestionado y así debe reconocérsele a la luz de la declaración contenida en la Disposición final cuarta, n. ${ }^{\circ} 3$ de la propia LORCA y atendiendo también a su contenido material. Con independencia del modelo representativo y de participación de grupos para la composición de la Asamblea General que específicamente ha previsto la Ley cántabra y al que ya nos hemos referido, es claro que nada cabe objetar al referido art. 2.3, párr. $3 .^{\circ}$ de la LORCA, desde la posible extralimitación competencial del Estado, pues, justamente en atención al principio democrático que inspira la finalidad central de la regulación de los órganos de gobierno de las Cajas de Ahorro, ha adoptado una regla que se ajusta plenamente a aquél. La regla del reparto proporcional de la representación correspondiente a las personas o Entidades fundadoras de las Cajas de Ahorro entre los restantes grupos -cualesquiera que éstos sean en cada casovincula, por tanto, a la competencia normativa de las Comunidades Autónomas, dado su carácter de norma básica de la materia.

En consecuencia, la contradicción existente entre el precepto básico estatal y el precepto autonómico, debe resolverse en esta ocasión accediendo a la declaración de inconstitucionalidad del art. 15.3 de la Ley 1/1990 cántabra" (vid. f. j. 6).

«También se constata en su misma literalidad, una contradicción explícita entre el art. 29.2, segundo párrafo, de la misma Ley cántabra y el art. 22.1 de la LORCA. Mientras que este segundo, en relación, además con el 
art. 14 de la misma Ley, establece que los miembros de la Comisión de Control serán "elegidos por la Asamblea General entre sus miembros", a propuesta de los Consejeros Generales de los diversos grupos de representación, el art. 29.2, segundo párrafo, de la Ley Autonómica dispone que "el sistema de elección de los representantes (de los diversos grupos en la Comisión de Control, debe entenderse) se efectuará mediante votación separada entre los distintos grupos que forman la Asamblea General".

El sistema previsto por la LORCA con el carácter de básico se asienta, pues, en lo sustancial, en los dos siguientes criterios: en primer lugar, en que el nombramiento de los vocales del Consejo de Administración y de los miembros de la Comisión de Control compete a la Asamblea General (art. 11.1 LORCA), y, en segundo lugar, en que en la designación deben respetarse determinados porcentajes de representación de los intereses colectivos, articulándose a tal fin un mecanismo de propuesta de candidatos para los diversos grupos representativos en los términos que establece el art. 14 de la LORCA.

Pues bien, la literalidad misma del precepto autonómico impugnado resulta, de este modo, inconciliable con las señaladas previsiones de la LORCA, lo que ineludiblemente determina su inconstitucionalidad» (vid. f. j. 7).

Fallo: 1. $\quad$ Estimar parcialmente el recurso de inconstitucionalidad n. ${ }^{\circ} 1518 / 1990$, párrafo segundo, de la Ley $1 / 1990$ de la CA de Cantabria, desestimándolo en todo lo demás.

2. ${ }^{\circ}$ Desestimar el recurso de inconstitucionalidad $n .^{\circ} 432 / 1992$.

(Sentencia n. ${ }^{\circ}$ 60/1993, de 18 de febrero. BOE 22-3-1993. M. Rodriguez-Piñero y Bravo-Ferrer).

4. Recurso de inconstitucionalidad 2461/1990, interpuesto por el Presidente del Gobierno contra los arts. 35.1, aps. a) -inciso final-, b) 2 y d); 39.2, 3 y 4, en conexión con los arts. 23.4, 43.4, 44, 53.5 y 59, párrafo 2. , frase final; 71 a) y 72 a) de la Ley del Parlamento de Canarias 13/1990, de 26 de julio, reguladora de las Cajas de Ahorro. El TC declara inconstitucionales y nulos los arts. 35.1.b) 2. ; 35.1.d); y 39.3 y 4 .

«El art. 35.1.d) de la Ley canaria establece que no podrán ejercer el cargo de Consejero general ni actuar como compromisarios "los Presidentes, Consejeros, Gerentes, Asesores y asimilados de otras Entidades de cré- 
JURISPRUDENCIA

dito, ahorro o gestión financiera", mientras que el art. 8.b) de la LORCA establece que no podrán ostentar el cargo de compromisarios o Consejero general, tanto esos cargos, de establecimientos o instituciones de crédito, como los mismos cargos "de Corporaciones o Entidades que propugnen, sostengan o garanticen instituciones o establecimientos de crédito o financieros, o las personas al servicio de la Administración del Estado o las Comunidades Autónomas con funciones a su cargo que se relacionen directamente con las actividades propias de las Cajas de Ahorro". Hay que tener en cuenta, sin embargo, que el art. 35.1,e) hace referencia específica a los funcionarios al servicio de la Administración de la CA con funciones relacionadas directamente con las actividades de las Cajas de Ahorro.

No cabe duda sobre el carácter básico del precepto estatal, y que el mismo, aunque contiene una regulación pormenorizada, no excluye ni impide una intervención adicional del legislador autonómico, que ha de respetar sin embargo lo establecido en la legislación básica del Estado, que a efectos de las determinaciones de las incompatibilidades para ser compromisario o Consejero general, establece un mínimo común para todo el Estado, que ha de ser respetado y es indisponible para la Ley autonómica (STC 49/1988, f. j. 21).

El precepto autonómico impugnado establece una regulación completa, minuciosa y cerrada del régimen de incompatibilidades para sustituir la normativa básica estatal en la materia, en este caso de carácter mínimo. Para ello ha incorporado sustancialmente lo dispuesto en el art. 8 de la LORCA, pero con supresiones significativas, al no hacer referencia, a diferencia de lo dispuesto en la norma estatal, ni a los funcionarios del Estado, ni a determinados cargos de Corporaciones o Entidades relacionadas con las Entidades de crédito pero distintas de éstas. El mero contraste o comparación entre el texto de la norma autonómica y de la norma básica estatal evidencia que la primera restringe y modifica el alcance y contenido de la Ley estatal y, aunque sea por defecto, la contradice abiertamente, tanto en su letra como en su principio (...) Ello confirma que el precepto autonómico impugnado restringe una causa de incapacidad e incompatibilidad fijada por la normativa básica del Estado, sin que sea óbice para ello, aparte de la inseguridad jurídica que genera este modo de legislar (STC 154/1989), el que la contradicción con la norma básica del Estado no lo sea por exceso, sino por defecto, dado que ello supone en todo caso la contradicción del art. 35.1,d) de la Ley autonómica impugnada con lo previsto en el art. 8 de la LORCA.

Por lo tanto, el art. 35.1,d) de la Ley canaria $13 / 1980$ es inconstitucional y ha de ser declarado nulo" (vid. f. j. 3). 
«El art. 35.1.b) $2 .^{\circ}$, de la Ley canaria, a diferencia del art. 8.D).b) de la LORCA vincula la incompatibilidad por impago de deudas a la Caja a que el mismo se produzca "con contumacia" y a que se encuentren "reconocidas, en todo caso, por Sentencia firme".

Pues bien, las precisiones que el legislador autonómico ha incorporado en la tipificación de la referida causa de incompatibilidad, ceñida por la norma básica estatal al "impago de deudas de cualquier clase frente a la Entidad", desbordan los límites a los que queda constreñido el ejercicio de la competencia autonómica, pues suponen una restricción del supuesto al que el legislador estatal ha anudado la incompatibilidad, fruto sin más del impago de deuda y no, claro es, del hecho de persistir con contumacia en el impago aun tras haber sido reconocidas por sentencia firme. No se trata, por tanto, de una precisión o desarrollo que perfile razonablemente la causa de incompatibilidad, sino que ésta se cualifica de tal manera que restringe indebidamente los supuestos reconducibles a la misma. Consecuentemente, debe estimarse inconstitucional el art. $35.1, \mathrm{~b}), 2 .^{\circ}$ de la Ley impugnada» (vid. f. j. 4).

«La impugnación del art. 39.2, 3 y 4 de la Ley canaria se sustenta en que contradice lo dispuesto en el art. 12.2, párrafo primero, de la LORCA, al preverse un diferente quórum de asistencia y una distinta mayoría para la adopción de acuerdos de disolución y liquidación o fusión de Cajas de Ahorro (...).

El resultado al que, de este modo, se llega, supone una flagrante vulneración de la normativa básica estatal, que exige un quórum mínimo de asistencia - la mayoría de los miembros de la Asamblea General-y, a la vez, un voto cualificado -el favorable de los dos tercios de los asistentes- (art. 12.2, en relación con el el art. 11.3 de la LORCA). Dada la contradicción existente entre la norma básica del Estado y la norma autonómica, que ineludiblemente ha de resolverse a favor de la estatal, ha de declararse la inconstitucionalidad de los núms. 3 y 4 del art. 39 de la Ley autonómica en cuanto omiten la adopción de los acuerdos a los que se refiere el art. 23.4 de la misma Ley autonómica. La inconstitucionalidad no puede extenderse, sin embargo, al núm. 2 del referido art. 39 , por cuanto éste se ajusta plenamente a lo dispuesto por el art. 12.1, último párrafo, de la LORCA» (vid. f. j. 5).

Fallo: $1 .^{\circ}$ Declarar que el art. $\left.35.1, \mathrm{~b}\right), 2 .^{\circ}$ de la Ley del Parlamento de Canarias 13/1990, de 26 de julio, reguladora de Cajas de Ahorro, es inconstitucional y, por tanto, nulo. 
JURISPRUDENCIA

2. Declarar que el art. 35.1,d) de la Ley impugnada es inconstitucional y consiguientemente nulo.

3. Declarar que son inconstitucionales y por consiguiente nulos, los núms. 3 y 4 del art. 39 de la Ley impugnada.

4. Desestimar el recurso de inconstitucionalidad en todo lo demás.

(Sentencia n. ${ }^{\circ} 61 / 1993$, de 18 de febrero. BOE 22-3-1993. M. RodriguezPiñero y Bravo-Ferrer).

5. Recurso de inconstitucionalidad 814/1991, interpuesto por el Presidente del Gobierno contra los arts. 14.2; 35.1 a); 36; 58 y 60 de la Ley de las Cortes de Aragón 1/1991, de 4 de enero, reguladora de las Cajas de Ahorro en Aragón. El TC declara inconstitucionales y nulos los arts. 14.2; 35.1 a), en su inciso "de nacionalidad española»; 36 y 60.1.

«El art. 14.2 de la Ley aragonesa establece que "la absorción por una Caja aragonesa de otra Caja de Ahorro requerirá el voto favorable de la mayoría absoluta de los miembros del Consejo de Administración de la Entidad absorbente y la mayoría simple de su correspondiente Asamblea.

El Abogado del Estado considera que el referido precepto conlleva una extralimitación competencial por cuanto la LORCA (en su art. 12.2 puesto en relación con el art. 11.3) ha previsto con el carácter de norma básica unos quórum de asistencia y de voto diferentes para la adopción de acuerdos por las Asambleas Generales sobre fusión de las Cajas de Ahorro. Concretamente la norma básica estatal ha establecido un quórum mínimo de asistencia - la mayoría de los miembros de la Asamblea General - y a la vez, un voto cualificado, el favorable de los dos tercios de los asistentes (...). Así pues, la previsión autonómica cuestionada, el art. 14.2 impugnado, establece un quórum de asistencia y una mayoría más limitada, que no respeta la norma básica estatal, que no permite reducir las exigencias de quórum de asistencia y de voto cualificado cuando de una absorción por fusión se trate. El precepto, por ello, ha de ser declarado inconstitucional» (vid. f. j. 2).

"El art. 35.1,a) se impugna en cuanto establece como requisito que habrán de reunir los Consejeros generales el tener la nacionalidad española. 
El art. 15 de la LORCA, por remisión en este punto al art. 7. ${ }^{\circ}$ de la misma Ley, impuso idéntica exigencia — ser persona física de nacionalidad española-, pero no es menos cierto que, con posterioridad, el art. 3. ${ }^{\circ}$ del Real Decreto Legislativo 1298/1986, de 28 de junio, por razón de adaptación a la legislación de la Comunidad Económica Europea (Directiva 73/183, de 28 de junio, y 77/780, de 12 de diciembre) suprimió dicho requisito dando nueva redacción al art. 7.1,a) de la LORCA ("ser persona física con residencia habitual en la región o zona de actividad de la Caja"), con lo que la posterior Ley autonómica que se impugna, al no ajustarse a la norma básica estatal, incurre en inconstitucionalidad» (vid. f. j. 3).

«La inconstitucionalidad del art. 36 de la Ley aragonesa vendrá dada por no haber reproducido en su totalidad los supuestos de incompatibilidad previstos por la norma estatal y, más en concreto, los contenidos en las letras a) -en lo relativo a quienes hubiesen sido sancionados por infracciones graves-, b) y c) del art. $8 .^{\circ}$ de la LORCA, de carácter básico (...) Este Tribunal ha afirmado que las causas de incompatibilidad que contiene el art. $8 .^{\circ}$ LORCA "han de ser respetadas por las legislaciones autonómicas, si bien éstas pueden añadir otros motivos o precisiones razonables, o desarrollar con más detalle los establecidos en la Ley" (...) El precepto autonómico contradice y no respeta la legislación básica del Estado al eliminar supuestos previstos por el legislador estatal» (vid. f. j. 4).

"Idéntico motivo de impugnación al que acaba de analizarse se esgrime por el Abogado del Estado a propósito del art. 60 de la Ley aragonesa, trayéndose ahora a colación lo dispuesto en el art. $24.1,3 .^{\circ}$ y $8 .^{\circ}$ de la LORCA (...)

La contradicción entre el art. 60.1 de la Ley aragonesa 1/1991 y lo dispuesto en los arts. $24.1,3 .^{\circ}$ y $8 .^{\circ}$ de la LORCA, resulta clara, pues se suprime el párrafo que la Ley estatal dedica al control sobre la Obra Benéfico Social y se desconecta el requerimiento de convocatoria de la Asamblea General del supuesto de suspensión de la eficacia de los acuerdos, exigiéndose además, para tal requerimiento en la Ley aragonesa un "quórum" muy cualificado de dos tercios de sus miembros. Con toda evidencia, tales exclusiones o adiciones suponen que la Ley autonómica reduce o suprime dos funciones muy significativas que la legislación básica del Estado asigna a la Comisión de Control, que, no debe olvidarse, "tiene por objeto vigilar la actuación del Consejo de Administración" (STC 49/1988, f. j. 25). Esta supresión tiene una incidencia muy directa en el control de la corrección de la gestión de la 
תURISPRUDENCLA

Caja y en el aseguramiento de su solvencia. El propósito reductivo de la Ley autonómica se confirma, además, en la previsión contenida en el apartado h) de ese art. 60, que deja abiertas las facultades del órgano, pero refiriéndolas a otras funciones "que le atribuyan esta Ley o los Estatutos de la Caja", lo que en sus propios términos implicaría eliminar la aplicación de la legislación del Estado en esta materia.

En consecuencia, por estas razones, la enumeración del art. 60.1 de la Ley aragonesa 1/1991 es inconstitucional en cuanto contrario a lo dispuesto en la legislación básica del Estado, y, por ello, mediatamente al art. 149.1.11 ${ }^{\mathrm{a}} \mathrm{CE}$ » (vid. f. j. 5).

Fallo: 1. ${ }^{\circ}$ Declarar que el art. 14.2 de la Ley de las Cortes de Aragón $1 / 1991$, de 4 de enero, es inconstitucional y, por tanto, nulo.

2. Declarar que el inciso "de nacionalidad española" del art. 35.1 ,a) de dicha Ley, es inconstitucional y, por tanto, nulo.

3. Declarar que es inconstitucional y, por consiguiente nulo, el art. 36 de la citada Ley.

4..$^{\circ}$ Declarar que es inconstitucional $y$, por consiguiente nulo, el núm. 1 del art. 60 de la citada Ley.

5. Desestimar el recurso de inconstitucionalidad en todo lo demás.

(Sentencia n. ${ }^{\circ}$ 62/1993, de 18 de febrero. BOE 22-3-1993. M. Rodríguez-Piñero y Bravo-Ferrer).

\section{B) Transportes terrestres}

1. Conflicto positivo de competencias $649 / 1986$, planteado por el Gobierno Vasco, frente a determinados artículos de la Orden 7/1986, de 27 de enero, del Ministerio de Defensa, por la que se aprueba la normativa aplicable al transporte de mercancías peligrosas por carretera en vehículos de las Fuerzas Armadas. Se trata de una norma que se inscribe dentro de la regulación de la seguridad del tráfico y circulación de vehículos de motor, materia reservada al Estado en el 149.1.21 $C E ;$ de este modo no se vulneran las competencias autonómicas sobre protección civil.

"La Orden controvertida es desarrollo de la Disposición adicional del RD 1723/1984, de 20 de junio, sobre Reglamento Nacional de Trans- 
porte de Mercancías Peligrosas. La peculiaridad de la norma que se impugna reside en que se refiere a un tipo específico de vehículos, los pertenecientes a las Fuerzas Armadas, que se someten en este aspecto (como los de las Fuerzas de Seguridad del Estado) a una normativa propia. La Orden en cuestión viene a regular las condiciones que deben reunir los conductores de determinados tipos de vehículos de las Fuerzas Armadas (arts. 1 a 3), las normas de circulación a seguir por tales vehículos (arts. 4 a 6 ), las normas para caso de accidente (arts. 7 a 11) y los permisos necesarios y los controles preceptivos que deben adoptarse por los vehículos de que se trata (arts. 12 a 15). Nos encontramos, pues, ante una norma que, en principio, se inscribe en sus diversos aspectos, dentro de la regulación de la seguridad del tráfico y circulación de vehículos de motor, materia ésta que el art. 149.1.21 CE reserva a la competencia exclusiva del Estado.

La Comunidad Autónoma que plantea el conflicto sostiene que el transporte de mercancías peligrosas debe incluirse en el ámbito de la protección civil. Ahora bien, esa afirmación no resulta aceptable como fundamento de la competencia autonómica en el presente caso. Como se recoge en la Exposición de Motivos de la Ley 2/1985, de 21 de enero, de Protección Civil, ésta debe entenderse como "protección física de las personas y de los bienes en situación de grave riesgo colectivo, calamidad pública o catástrofe extraordinaria en la que la seguridad y la vida de las personas puedan peligrar y sucumbir masivamente". Y, de la consideración de los artículos que se cuestionan no cabe concluir que se refieran a situaciones de ese tipo, como supuesto normal de su aplicación: pues la regulación que en ellos se contiene versa sobre eventualidades que no se asocian normalmente con la creación de riesgos catastróficos extraordinarios" (vid. f. j. $\left.4^{\circ} .^{\circ}\right)$

Fallo: Declarar que pertenece al Estado la titularidad de la competencia controvertida.

(Sentencia n. ${ }^{\circ}$ 2/1993, de 14 de enero. BOE 12-2-1993. L. Lopez Guerra). 